\title{
SIMULATING DISTRIBUTION OF EMERGENCY RELIEF SUPPLIES FOR DISASTER RESPONSE OPERATIONS
}

\author{
Young M. Lee \\ Soumyadip Ghosh \\ Markus Ettl \\ IBM T.J. Watson Research Center \\ 1101 Kitchawan Road \\ Yorktown Heights, NY 10598, USA
}

\begin{abstract}
In the event of disasters such as hurricanes, earthquakes and terrorism, emergency relief supplies need be distributed to disaster victims in timely manner to protect the health and lives of the victims. We develop a modeling framework for disaster response where the supply chain of relief supplies and distribution operations are simulated, and analytics for the optimal transportation of relief supplies to various POD (Points of Distribution) are tested. Our simulation model of disaster response includes modeling the supply chain of relief supplies, distribution operations at PODs, dynamics of demand, and progression of disaster. Our analytics optimize the dispatch of relief supplies to PODs and cross-leveling among PODs. Their effectiveness is estimated by the simulation model. The model can evaluate a wide range of disaster scenarios, assess existing disaster response plans and policies, and identify better approaches for government agencies and first responders to prepare for and respond to disasters.
\end{abstract}

\section{INTRODUCTION}

Recent natural and man-made disasters such as Hurricane Katrina in 2005, Hurricane Gustav in 2008, flooding in Iowa in 2008, flooding in North Dakota in 2009, earthquake in the Sichuan Province of China in 2008, U.S. anthrax attack in 2001 and the possibility of a pandemic of H1N1 influenza in 2009 made us realize how important it is to have effective disaster preparedness and response planning. Larson et al. (2006) provide a historical review of five major disasters - the Oklahoma City bombing in 1995, the crash of United Flight 232 in 1989, the Sarin attach in the Tokyo subway in1995, Hurricane Floyd in 1999 and Hurricane Charlie in 2004 - and stress the need for operations research models to improve preparedness for and response to major emergencies. One of the responsibilities of federal and local governments is to distribute emergency relief supplies such as water, meals, blankets, generators, tarps and medicine to disaster victims in the event of various natural and man-made disasters such as hurricanes, earthquake, flood and terrorism. Emergency relief operations may need to cover millions of people in a short period of time. For example, it is desired that water and meals reach victims within three days to prevent serious health hazard and death. For a wide-spread smallpox attack, the vaccination of all in potential contact is recommended within 4 days of exposure, and in the event of an anthrax outbreak, the distribution of antibiotics is recommended within two days of the event (AHRQ - Agency for Healthcare Research and Quality, 2004). Adverse consequences of ineffective distribution planning can include death, sickness and social disorder. For example, the confirmed death toll from hurricane Katrina in 2005 is over 1,300 victims, in addition to $\$ 200$ billion of damages. A better response plan would have reduced the death toll (Iqbal 2007). Therefore, careful planning of distribution of emergency supplies considering various risk factors and uncertainty is important because it will influence the lives of many people. The task of providing immediate disaster relief and recovery assistance also requires coordination between local and the federal government (Iqbar 2007).

The supply chain of the relief supplies differs from commercial supply chains in many ways including the following factors; a huge surge of demand with a short notice, damaged/congested roadways, chaotic behavior of demand (victims), breakdown of infrastructure such as communication networks, short lead times, and many other unknowns and uncertainties. Preparing for a large disaster such as a hurricane is difficult because predicting where it will strike with accuracy is impossible. For example, based on the National Hurricane Center's (NHC) average forecast error, the highest probability that a hur- 


\section{Lee, Ghosh and Ettl}

ricane is expected to make landfall within 65 nautical miles radius of a certain area in 48 hours is only 20-25\% (NHC, 2009). Therefore, for the HCLP (high-consequence, low-probability) events, a new breed of analytical models is needed to better understand the disasters and to better prepare for and respond to disasters. Also, unlike research in traditional supply chains such as inventory management, distribution network modeling and transportation planning, which can be carried out in purely theoretical aspects, meaningful analytical models for disaster response cannot be developed without intimate knowledge of the government organizations, their operations and politics involved (Green and Kolesar 2004).

Disaster preparedness and response modeling consist of four areas: supply chain model, POD distribution model, demand model and disaster model. The supply chain model describes the flow of disaster relief supplies from federal government suppliers to distribution centers (DC), to federal staging areas to staging areas of local governments, and finally to the points of distribution (POD). The POD distribution model describes how relief supplies are distributed to victims who come to a POD to receive supplies. The demand model describes the occurrence of disaster victims needing relief supplies with respect to time and location. The disaster model describes the arrival and progression of disasters with respect to time and location. The disaster model affects the other three models. It influences the number of victims (i.e., the demand model) and activation of supply chain nodes and transportation (i.e., the supply chain model) and the efficiency of POD operations (i.e., POD distribution model). All four models together contribute to the impact of disasters and overall effectiveness of disaster preparedness and response plans and operations. For comprehensive analysis of disaster preparedness and response, any potentially useful analytic models should also be evaluated and tested in the simulation environment where all four areas are modeled.

Analytic models have been developed and used since the 1960s for many types of emergency responses and provided important insights, policies and procedures for cities and other government organizations, including very successful models for the NYFD (New York City's Fire Department) on dynamic location model of firefighters (Kolesar and Walker 1973) and the NYPD (New York City's Police Department) on the Hypercube queuing model for police emergency response system (Larson 1974). Larson (2002), Green and Kolesar (2004) and Wright et al. (2006) give a good survey of operations research models and applications under the umbrella of homeland security and emergency response. Most of the published research focuses narrowly on one or more of the four modeling areas, and is also limited to a particular type of disaster.

Bravata et al. (2006) studied strategies for stockpiling and dispensing for anthrax bioterrorism, and modeled regional and local supply chain for antibiotics and medical supplies to estimate mortality. The authors modeled the supply chain, dispensing, disease progression model and the resulting demand model specific to an anthrax attack. They developed a simulation model to evaluate four types of strategies: event detection, local (POD) dispensing capacity, local inventory of antibiotics, and national inventory. They concluded that the critical determination of mortality following anthrax bioterrorism is the local dispensing capacity (throughput rate). Wein and Liu (2005) developed a supply chain model of milk to analyze the impact of a bioterrorism attack of botulinum toxin, which has a potential death rate of $50 \%$ with a chance of 400,000 people contaminated. Their model is based on a systems of linear first-order differential equations for eight stages of the supply chain from cows to farm tanks, truck, silo, processing lines, packaged milk, distributors, retailer and finally to consumers. They recommended investment in prevention through enhanced security, in the heat pasteurization process and in-process testing for toxins. Detailed multi-echelon supply chain models for natural disasters such hurricane, however, have not been developed.

For POD dispensing operations, models have been developed for bioterrorism response such as smallpox and anthrax attach including the modeling work for the Los Angeles County (Rickter et al. 2007), Montgomery County (Aeby et al. 2006) and the city of San Antonio (Miller et al. 2006). There are also some guidelines on POD plan and operation issued by the U.S. Government. CDC (2007) published a guideline for planning for POD operation in 2001, and AHRQ (2004) published a planning guide for mass prophylaxis and public health preparedness in 2004. Most of these models focus only on POD operations without modeling supply chain operations, demand dynamics and progression of disaster. Most of POD distribution models use discrete-event simulation, capacity planning models or queuing networks to analyze and improve clinic operations at POD locations with focus on the layout of the clinic, resource, capacity, speed of dispensing and traffic (Hupert at al. 2002; Aaby et al. 2006; Lee at al. 2006; Lee 2008; Whitworth 2006). These models do not include the distribution of medical supplies from federal government inventory to staging warehouses or to POD sites. Lee (2008) developed a simulation model that includes shipment of emergency medical supplies to PODs from a city-owned RSS (Receiving, Storing and Staging) warehouse in addition to POD operational model. He reported that cross shipping of vaccines or antibiotics among PODs can improve the coverage when the overall supply is limited or when there is an imbalance between supply and demand at PODs.

Demand for medical supplies such as vaccines and antibiotics for cases of bioterrorism attacks such as smallpox and anthrax is typically estimated by disease progression models (Bravata et al. 2006; Craft et al. 2005; Hupert et al. 2002; Kaplan et al. 2002; Wein et al. 2003). For other disaster such as hurricane, the number of victims who need to be supplied with emergency relief may require not only a model of disaster victims, but also a model of evacuation. A study by Baker (1991) based on the U.S. hurricanes from 1961 to 1989 showed that the evacuation behavior of people in the affected area depends 


\section{Lee, Ghosh and Ettl}

on risk level, action by public authorities, housing, prior perception of personal risk and storm-specific threat factors. An example of research on evacuation modeling and planning is Lee et al. (2006b) who developed an optimization model for emergency evacuation by optimizing destination and route assignment. Ekici et al. (2008) developed a detailed SEIR disease spread model of pandemic influenza for the state of Georgia and estimated the (deterministic) demand from the disease model. The authors solved a hierarchical multi-time period capacitated facility location problem to find an optimal food distribution network for a state-level supply chain.

For disaster modeling, models have been developed that describe the spread of bioterrorism infection including models of anthrax (Bravata et al. 2006; Craft et al. 2005; Hupert et al. 2002; Wein et al. 2003) and smallpox (Kaplan et al. 2002; Miller et al. 2006). For other natural disasters such as hurricanes, developing a model that predicts the location of landfall, severity and progression is very difficult (Larson et al. 2006). Therefore, a simulation model that analyzes many different scenarios would be more useful than developing analytic prediction models that would have such low accuracy as to be unusable.

As indicated by Green and Kolesar (2004) from their experience in the NYFD-RAND Institute project, a simulation model for disaster response is the foundation on which new policies and tactics can be developed and evaluated. In order to develop useful analytics for disaster preparedness and response, we must first understand the impact of disasters, disaster response operations and the consequences of alternative policies of preparedness and response. Simulation is an excellent tool for this purpose. Simulation models also provide a virtual physical environment which is necessary for developing analytic models. They also serve as a testbed as real-life experimentation of analytical tools with actual disaster situations would be too difficult and risky. In our work, we develop a simulation framework which models all four areas described earlier; supply chain, POD distribution, demand and disaster.

This paper focuses more on detailed supply chain operations considering various stocking policies, transportation resources, speed and other resources. Although the modeling capabilities described in this paper are for a hurricane scenario, the simulation framework is intended to be general so that it can be used in modeling other types of natural and man-made disasters such as flood, earthquake, fire and bioterrorism. We developed analytics for the optimal dispatch of relief supplies from local staging areas to PODs and optimal cross-leveling among PODs. The analytics can mitigate potential imbalance between supply and demand in the supply chain, and lead to effective relief operations. The effectiveness of the analytics is evaluated by simulation which models the progression of disasters, supply chain of relief supplies, POD operations and demand dynamics. By modeling and simulating the disaster preparedness and response, we explore a wide range of disaster scenarios and find effective plans for protecting people in the affected area. The model we develop can be used to assess existing disaster response plans and policies and to identify better approaches for government organizations and first responders to better prepare for and respond to disasters.

The rest of the paper is organized as follows. In section 2, we present the simulation framework where supply chain, POD distribution, demand and disaster are modeled. Section 3 briefly describes the analytic models developed for optimal transportation of relief supplies to PODs. Then, in section 4, we present simulation results for several scenarios of disaster preparedness and response with varying settings and strategies of planning and operations, and also report the simulated benefits of deploying the analytics. Finally, in section 5, we summarize the lessons learned and present direction for future research.

\section{DESCRIPTION OF THE SIMULATION MODEL}

In this paper, we develop a simulation framework, called i-DRuM (IBM's Disaster Response simulation Model), for disaster preparedness and response. It has four components; supply chain model, POD distribution model, demand model and disaster model as shown in Figure 1. Although the simulation model described here is for scenarios of hurricane, the framework can be customized to other disaster responses. For the supply chain model, we simulate the flow of disaster relief supplies from suppliers of federal government to distribution centers (DC), to staging areas of federal government (e.g., NLSA - National Logistics Staging Area), to staging areas of local government (e.g., LSA - Logistic Staging Area or OSA - Operational Staging Area), and finally to the point of distribution (POD). The disaster relief supplies we focus here is water and MREs (Meal-Ready-to-Eat).

Depending on the type, location and severity of disaster, selected supply chain nodes, i.e, a certain number of suppliers, DCs, staging areas and PODs, are activated to handle the required supply chain. The POD distribution model describes how relief supplies are distributed to victims who come to PODs to receive the supplies. PODs for commodity supplies can be parking lots of schools or stores, and victims typically drive up and pick up boxes of supplies and drive away. PODs for medical supplies can be buildings such as schools, recreation centers, theaters, stadium and medical facilities etc. PODs require a number of workers (typically volunteers), machines such as folk lifts, triage for medical supplies and service queue 


\section{Lee, Ghosh and Ettl}

lines etc., and the overall throughput rate (processing rate for distribution or dispensing) depends on all the resources and setups. The demand model describes the occurrence of disaster victims needing relief supplies with respect to time and location. Depending on disasters, severity and response, the profiles for victims can have different peaks and durations. The demand model can also include modeling of evacuation, which describes number of victims leaving the disaster area. For hurricane, most coastal locations need to start evacuations by 48 hours in order to have them completed before the tropical storm-force winds arrive. (NHC, 2009). The victims who need emergency relief supplies are those who stay in the affected area and be impacted by the disaster. The disaster model describes arrival and progression of disasters with respect to time and location. The disaster model affects the other three models. It influences the number of victims (i.e., the demand model) and activation of supply chain nodes and transportation (i.e., the supply chain model) and the efficiency of POD operation (i.e., POD distribution model). The balance between supplies of disaster relief and demand of disaster victims are manifested as the coverage (i.e., percentage of victims receiving emergency supplies over time). All four models (supply chain, demand, POD distribution and disaster model) together influence the impact of disasters and overall effectiveness of disaster preparedness and response plans and operations. For a comprehensive analysis of disaster preparedness and response, any potential analytic models developed should be evaluated and tested in the simulation environment where all four areas are modeled.

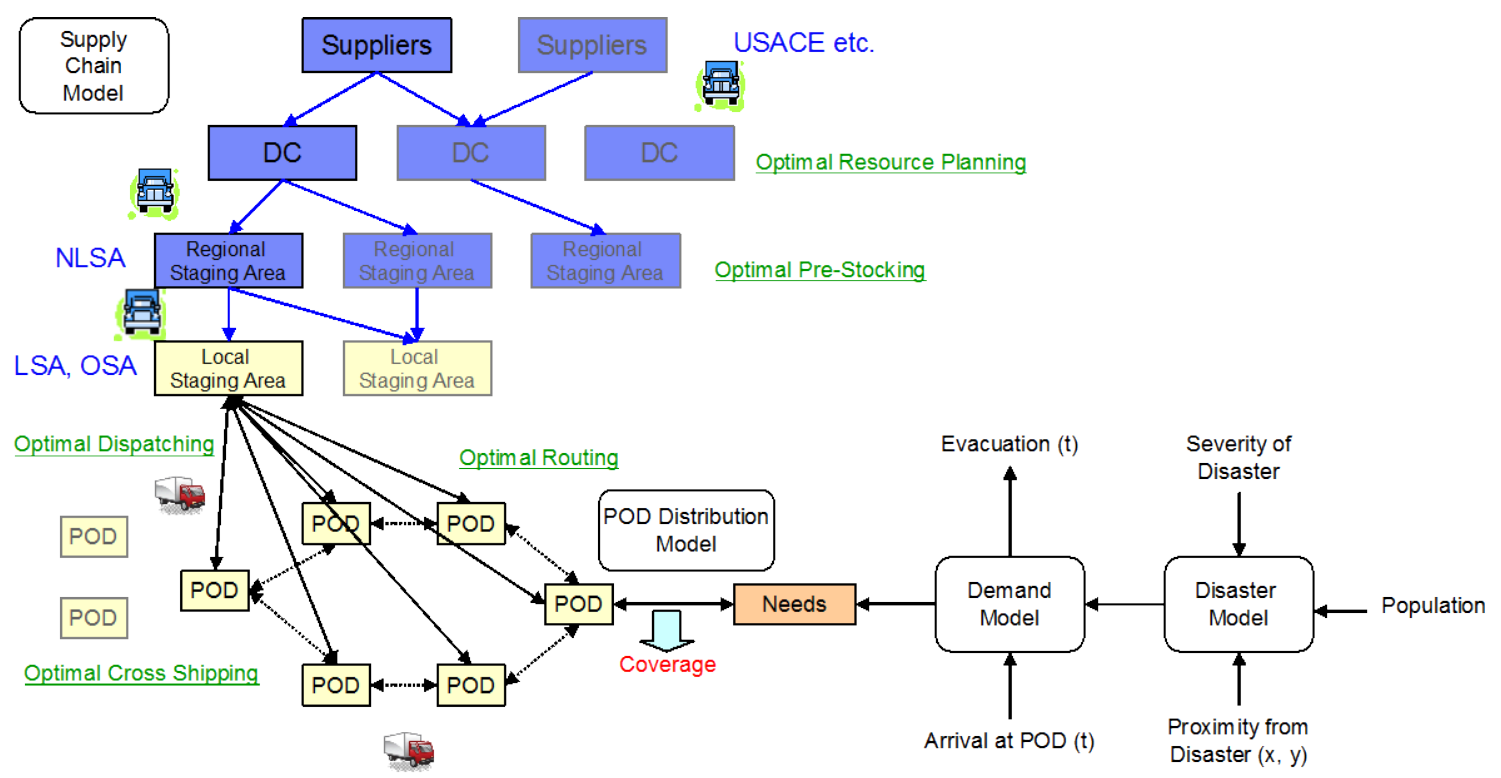

Figure 1: Models for Disaster Preparedness and Response

Various analytic tools can be useful in the supply chain. For instance, an optimal resource planning model can compute optimal levels of resources such as number of storage and staging facilities and number of trucks. An optimal pre-stocking model can compute pre-stocking levels of supplies at various DCs and staging areas. An optimal dispatching model can determine the destination POD of each truck that leaves the local staging area. An optimal routing model can determine optimal routes of trucks when delivering supplies to more than one PODs. An optimal cross shipping model can compute optimal time and quantities of cross shipping among PODs.

In addition to the flow of emergency supplies, there also is a flow of information among the hierarchy of command centers, which may include a central government command center (e.g., NRCC - National Response Coordination Center), regional commend center (e.g., JFO - Joint Field Office) and local command center (e.g., EOC- Emergency Operating Center) as shown in Figure 2. The command centers exchange information on supplies (inventory level, dispatching and arrival of trucks) and demand (number of victims and queues) throughout the relief operations. Communication is a key factor for effective response operations. Even if the supply chain is setup effectively, if incorrect or delayed information are communicated, the overall effectiveness of the disaster response operation will suffer. 


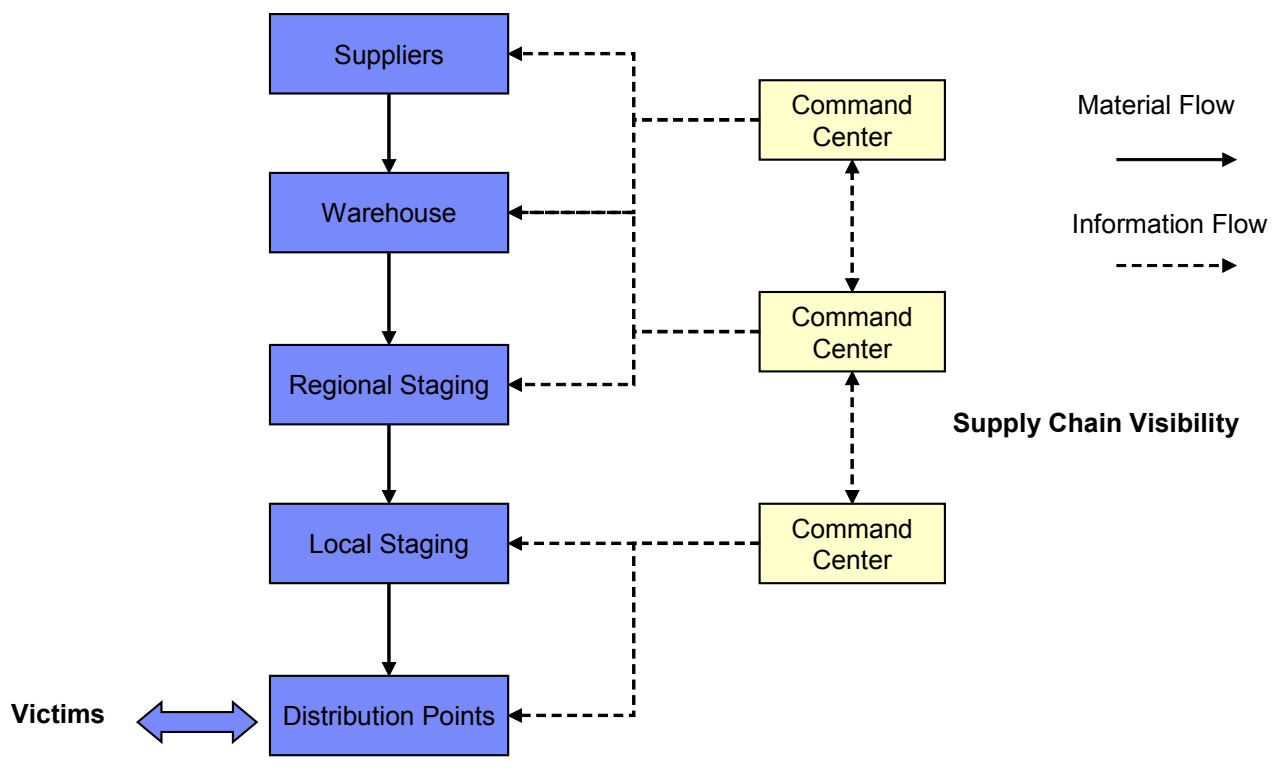

Figure 2: Material and Information Flow

Figure 3 shows the input screen for i-DRuM where various simulation parameters are set by a user for a hurricane. Figure 4 shows snapshots of the supply chain view and POD distribution view during the simulation of a hurricane disaster response.

Our disaster response modeling frame work consists of two parts; simulation and optimization. We develop a simulation model to understand the impact of disasters, disaster response operations and the consequence of alternative policies of preparedness and response. We also develop analytic models that can improve (optimize) supply chain and distribution operations, and we use the simulation model as testbed for the analytics.

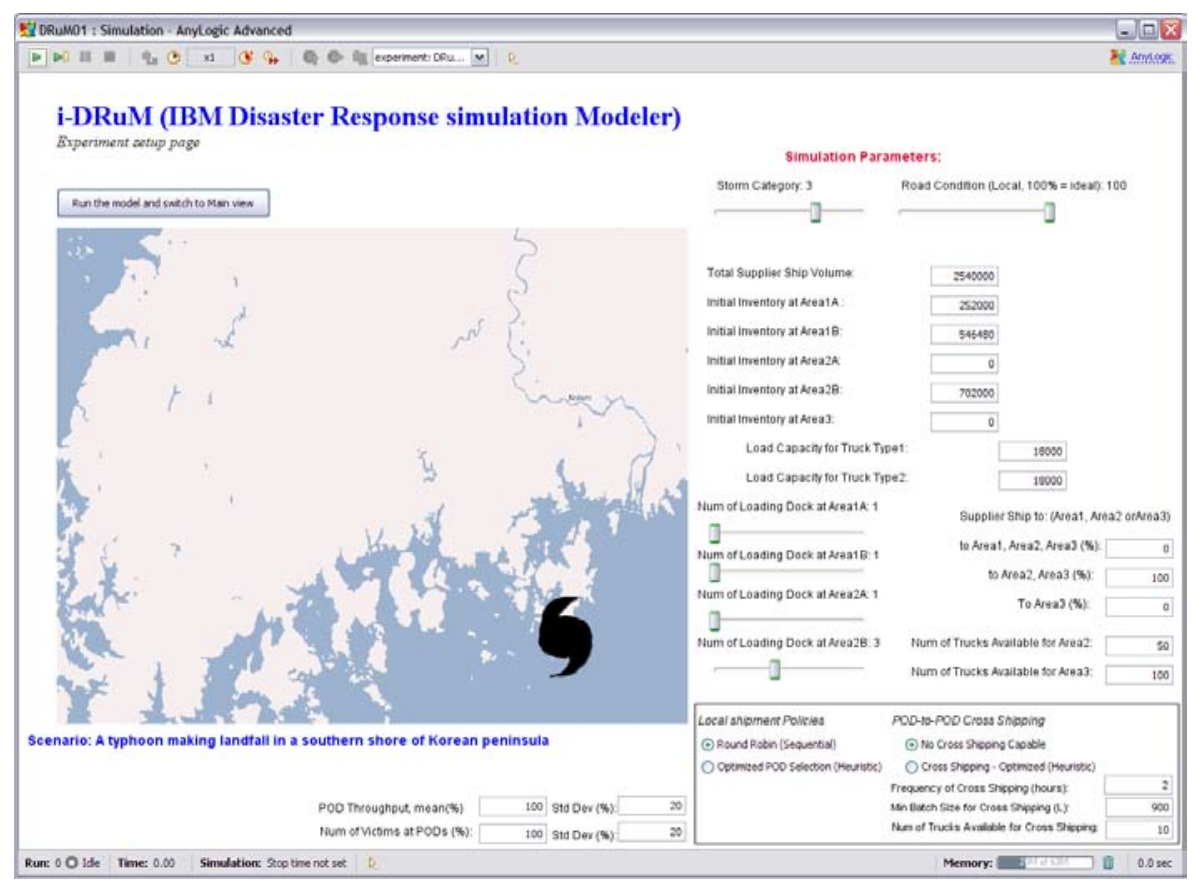




\section{Lee, Ghosh and Ettl}

Figure 3: Input Screen of i-DRuM
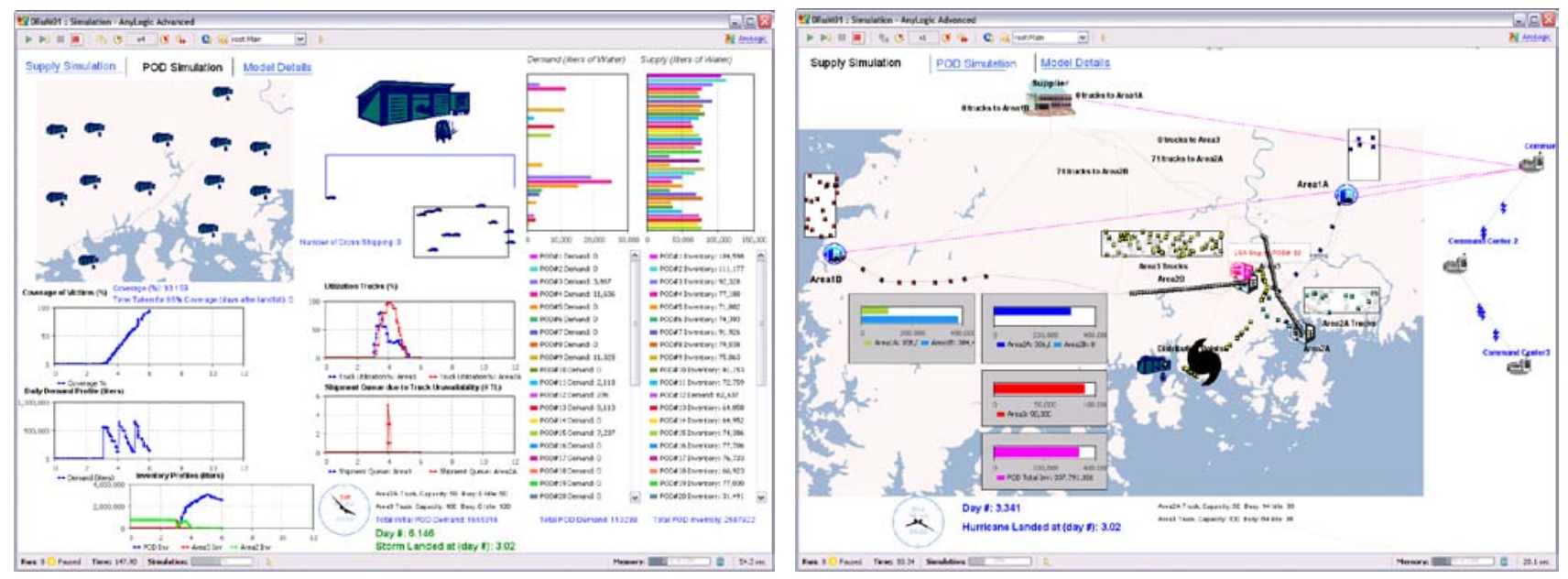

Figure 4: Snap Shots of i-DRuM Simulation

\section{ANALYTIC MODELS FOR TRANSPORTING RELIEF SUPPLIES TO POD}

In most disaster situations, demand from victims exhibits high uncertainty and variability. Disaster relief supplies will reach different POD locations at different speed and with different quantities. Therefore, during disaster response operations there will be an imbalance between supply and demand. For example, certain PODs will experience shortage of supplies and certain other POD location will experience surplus during disaster response operations. In order to reduce the imbalance between the demand and supply and improve the effectiveness of distribution, we developed two analytical models: an optimal dispatching model and an optimal cross shipping model.

The optimal dispatching model determines the best destination POD for each shipment from local staging area, e.g., RSA, considering: number of expected victims in each POD, supply (on-hand Inventory, In-transit inventory), transit time (distance, road conditions etc.), POD throughput rate for distributing emergency supplies. The optimal dispatching method outperforms round robin dispatching, which is a typical method for RSA outbound shipment for many government disaster response plan. In round robin dispatching, trucks from a local staging area willvisit PODs in pre-determined sequence. The mathematical description of the optimal dispatching model is not part of this paper, and it will be described in a subsequent paper.

The optimal cross shipping (or cross leveling) model determines the most effective cross leveling shipments (details include time to ship, origination POD, destination PODs, cross leveling quantity) by considering the following factors: forecast of expected victims in each POD, on-hand inventory, in-transit inventory to PODs, transit time (distance, road conditions), availability and capacity of cross shipping trucks, POD throughput, minimum shipment size for cross leveling and frequency of cross leveling, etc. Cross shipping is especially effective when the local staging area is located far away from POD location or there are damage or heavy traffic in roadways. The mathematical model of the optimal dispatching model will also be described in a subsequent paper. The optimal dispatching and cross shipping can be solved together if the same trucks can be used for both shipment between staging area and PODs and cross shipping among PODs. In i-DRuM, users can selectively activate optimal dispatching and cross shipping to investigate the effectiveness of each method in various disaster scenarios.

\section{SIMULATION EXPERIMENTS AND RESULTS}

\subsection{Simulation Setting}

In the following simulation experiment, we simulate that a category 2 hurricane which is making landfall in the U.S. Gulf coast region and is heading north. In this setting, we model the distribution of two key commodities: water and MRE. The 


\section{Lee, Ghosh and Ettl}

supply chain has two contracted vendors, each of which supplies a pre-stocked quantities of a single commodity. In this setting, 2 DCs, 1 NLSA, 1 RSA and 22 PODs are activated.

For water, the distribution quantity is 3 liters per person, and each truck can ship up to 18,000 liters (4,750 gallons) of water. For MREs, the distribution quantity is 2 MREs per person per day, and each truck can ship up to 21,744 MREs per truck load. At each POD, victims typically arrive by car and take one day's supply of water and MRE for a family of 3 (i.e., 9 liters of water and 6 MREs). Victims arrive at a POD once a day for 3 days. Table 1 shows the pre-positioned supply at supply chain nodes for the base case scenario.

Table 1: Pre-positioned Supply for Base Case

\begin{tabular}{|c|c|c|}
\hline & Water (liters) & MRE (each) \\
\hline Vendor & $2,520,000$ & $1,200,000$ \\
\hline DC1 & 252,000 & 422,208 \\
\hline DC2 & 546,480 & 777,924 \\
\hline NLSA & 702,000 & 547,000 \\
\hline RSA & 0 & 0 \\
\hline
\end{tabular}

There are 3 types of PODs in this setting among the 22 PODs. There are 20 type I PODs, 1 type II PODs, and 1 type III POD. Different types of POD have different capacity of distributing the supplies to victims (throughput capacity). Type I PODs can handle a maximum throughput of 20,000 people/day, type II PODs have a maximum throughput of 10,000 people/day, and type III PODs havea maximum throughput of 5,000 people/day. The total expected demand in this scenario is 332,000 victims per day for 3 days. The corresponding total demand for the 3-day campaign is 2,988,000 liters of water and 1,992,00 MREs. Based on the pre-positioned supply shown in Table 1, the total supply for water is 4,040,000 liters (35\% more than the total demand) and 2,947,000 MREs (48\% more than the total demand). Table 3 shows number of trucks available for vendors, DCs, NLSA and RSA, available loading docks for outbound shipment for DCs, NLSA and RSA for each commodity.

Table 2: Resources at Facilities

\begin{tabular}{|l|c|c|}
\hline & Water & MRE \\
\hline Trucks for Vendor & Unlimited & unlimited \\
\hline Trucks for DCs & Unlimited & unlimited \\
\hline Trucks for NLSA & 50 & 50 \\
\hline Trucks for RSA & 50 & 50 \\
\hline Loading Dock Available at DC1 & 1 & 1 \\
\hline Loading Dock Available at DC2 & 1 & 1 \\
\hline Loading Dock Available at NLSA & 1 & 1 \\
\hline Loading Dock Available at RSA & 2 & 2 \\
\hline
\end{tabular}

\subsection{Base Case Simulation Results}

The most important performance metric that we evaluate in the simulation analysis is coverage, i.e., the percentage of victims receiving emergency supplies over time. We are particularly interested in finding out how long it takes to achieve $95 \%$ coverage. Typically $95 \%$ coverage should be reached within 3 days from the start of disaster (e.g., landfall of the hurricane). It is, of course, important to reach $100 \%$ coverage for disaster response operations. Other performance metrics that were evaluated in the simulation are inventory of emergency supplies at various locations (e.g., DC, NLSA, RSA and PODs) during the campaign, and resource utilization such as trucks.

For the base case simulation, $95 \%$ coverage was reached at 3.805 days after the landfall for water, and 3.18 days for MRE as shown in Figure 5. The coverage for MRE was better than water because each truck can ship more MREs per person than water. Each truck can carry 21,744 MRE which can supply more than 10,000 people per day while each truck can carry 18,000 liters which can supply 6,000 people per day. Moreover, MREs are $48 \%$ over-supplied while water is $35 \%$ oversupplied. The overall coverage of both water and MRE reached 100\% after around 4.5 days. Figure 6 shows the inventory of water in NLSA, RSA and total of PODs over time. Figure 7 shows the utilization of trucks for the NLSA and RSA. Note that the NLSA has 50 trucks dedicated for shipment from the NLSA to the RSA, and the RSA has 50 trucks dedicated for 


\section{Lee, Ghosh and Ettl}

shipments to PODs. The trucks of NLSA and RSA return to the origin after delivering each shipment until all the supplies are shipped. The utilization of RSA trucks increases to only about $20 \%$; however, that of NLSA reaches $100 \%$ between 2 and 3.75 days, during which the queue for NLSA outbound shipments builds up to 22 truck loads as shown in Figure 8.

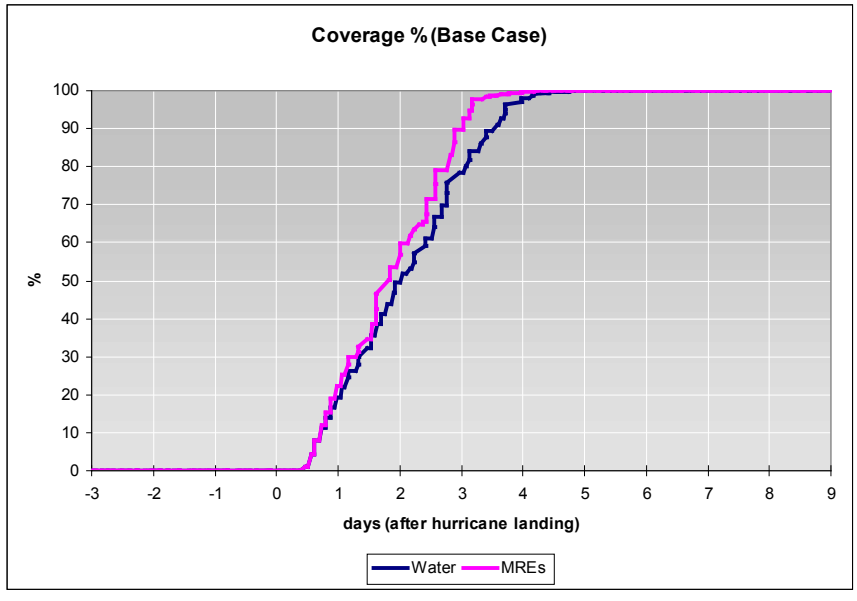

Figure 5: Coverage for Base Case

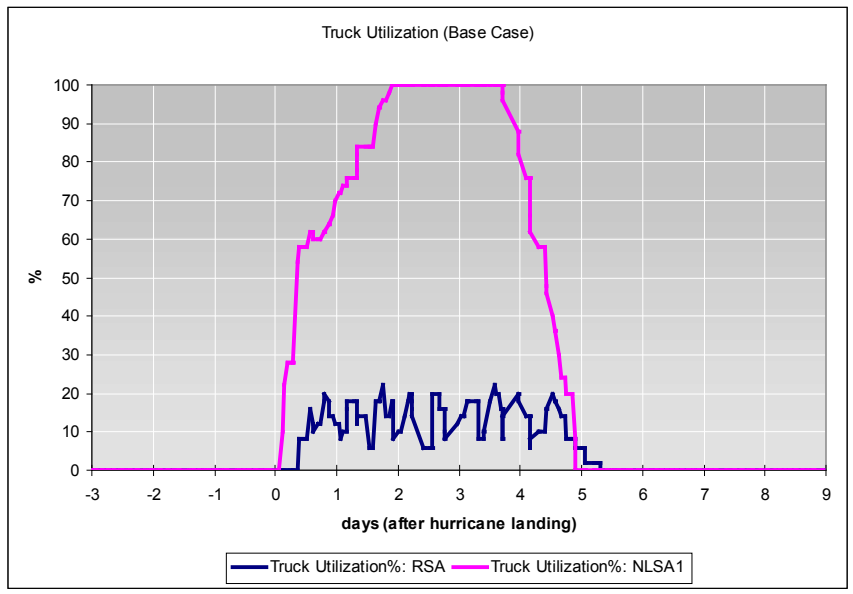

Figure 7: Truck Utilization at NLSA and RSA for Water

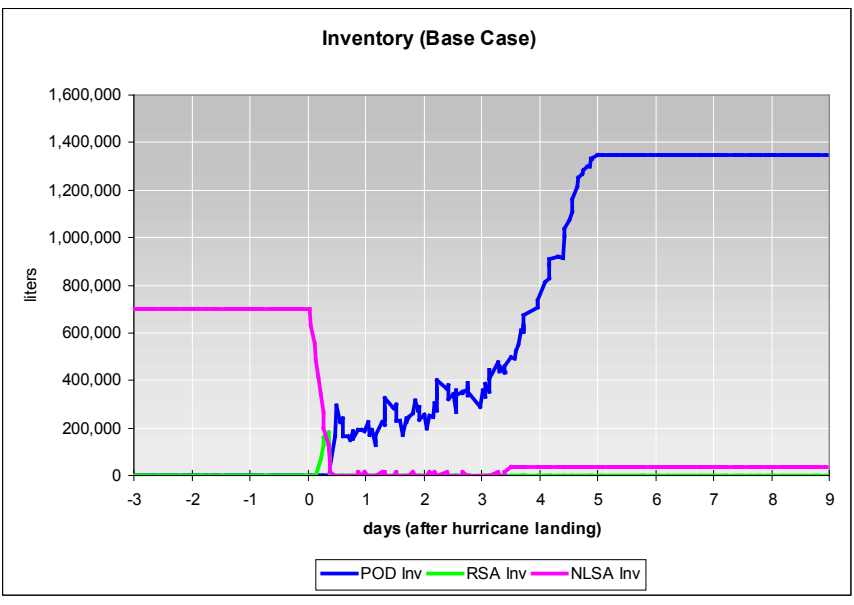

Figure 6: Inventory at NLSA, RSA and POD for Water

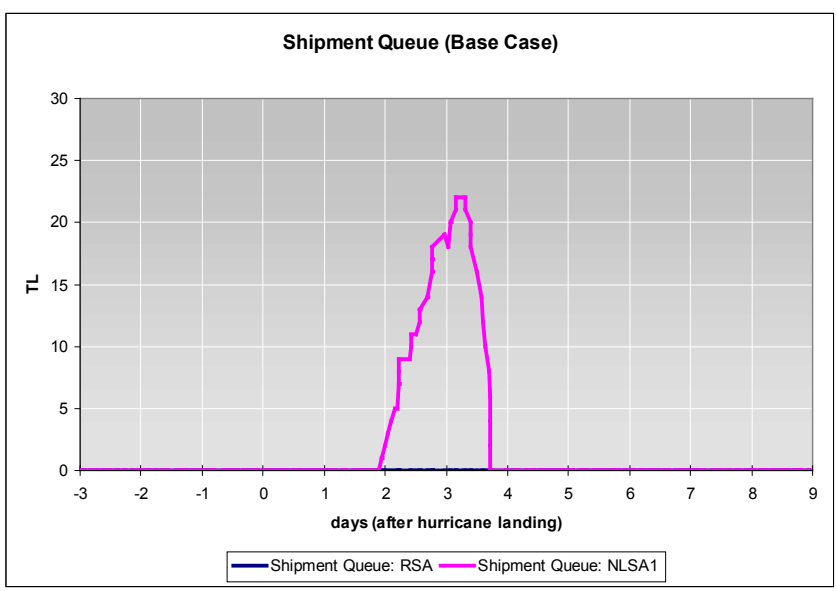

Figure 8: Shipment Queues Due to Truck Shortage for Water

\subsection{Pre-Positioning More Supply at DC and Staging Areas}

Because $95 \%$ coverage was obtained in 3.805 days for the base case, in this scenario we wanted to push more supplies into the supply chain by increasing the amount of pre-positioned supplies (water and MRE) to see whether it would improve the speed of coverage. First, we increased the pre-positioned supply quantity at DC1 and DC2 by 1 million liters, then at the NLSA by 1 million liters. The simulation results indicates that increasing pre-positioned supply at DC and NLSA does not improve coverage. Note that DC1 is located 578 miles away and DC2 is located 339 miles away from the NLSA. Therefore, it takes some time to move the extra supply to NLSA from DCs. The NLSA is located only 95 miles away from the RSA; however, the increase of pre-positioned supply creates significant backlog at the NLSA with the available 50 trucks. At peak times, up to 75 truck loads were waiting to be shipped from NLSA.

We then added 1 million liters to the pre-positioned supply at the RSA. Note than in the base case there was no prepositioned supply at the RSA. With pre-positioning, a 95\% coverage was reached after 2.889 days instead of 3.805 days. This is a significant improvement of almost 1 day to obtain $95 \%$ coverage. The RSA truck utilization went up to $50 \%$ from $20 \%$, but the number of RSA trucks, 50, are still sufficient. Figure 9 shows the profile of the coverage for this scenario and compares it with the base case. This experiment indicates that increasing supply quantities in the upstream supply chain 
(vendor, DC and NLSA) does not improve coverage, but downstream pre-positioning - such as at the RSA - significantly improve coverage as long as the POD throughput is not constrained. Pre-positioning supplies at an upstream supply chain node such as DC, however, is advantageous because it provides a risk pooling effect. Since it is difficult the predict where a disaster (e.g., hurricane) is going to strike, it is a good strategy to store supplies at upstream locations so that the supply can be shipped out to many potential disaster locations. Having pre-positioned supply in every possible disaster area (e.g., down stream locations such as RSA or POD) would improve the coverage for the actual disaster area but will result in high wastage in areas where the disaster does not land. Balancing the service level (coverage) and wastage of supplies can be controlled by the location and quantity of pre-positioned supplies in the supply chain, and simulations allow to study the effectiveness of prepositioning strategies in many circumstances.

\subsection{Lower Throughput at POD}

The speed of distribution at a POD, called POD throughput, depends on many factors such as the number of volunteers, equipment, traffic, location and size of a POD, behavior of victims etc., and is difficult to predict. In this experiment, we simulated the situation where the POD throughput is $20 \%$ lower than targeted throughput, and estimated the impact on coverage. Note that in the base case, we used a throughput of 20,000 victims/day for type I PODs, 15,000 victims/day for type II PODs, and 10,000 victims/day for type III PODs. For the 20\% lower throughput, $95 \%$ coverage was reached in 4.014 days instead of 3.805 days for the base case. The coverage profile for this experiment is shown in Figure 10. This simulation results indicate that when there is sufficient supply in the supply chain, POD throughput significantly affects the speed of coverage. Adding or dropping more PODs would have a similar effect.

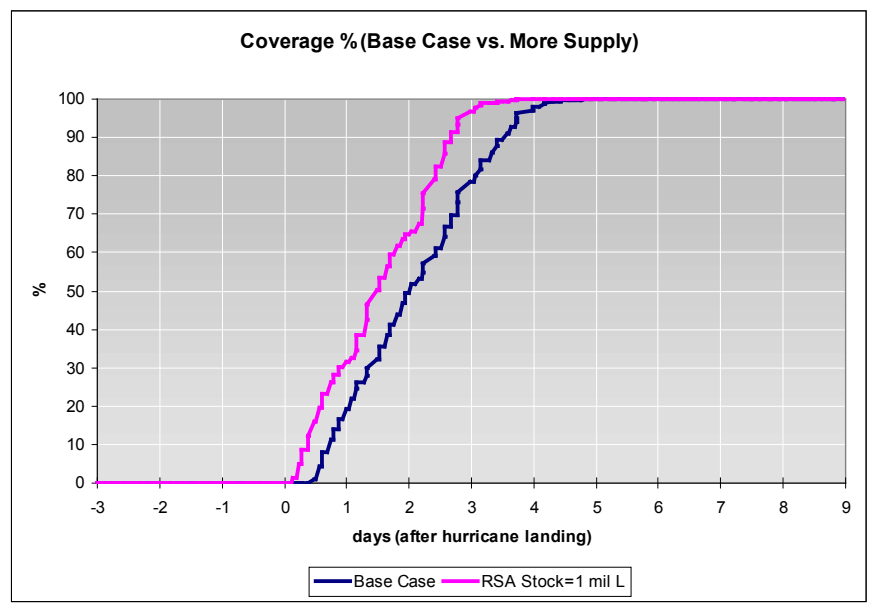

Figure 9: Coverage with RSA Pre-position

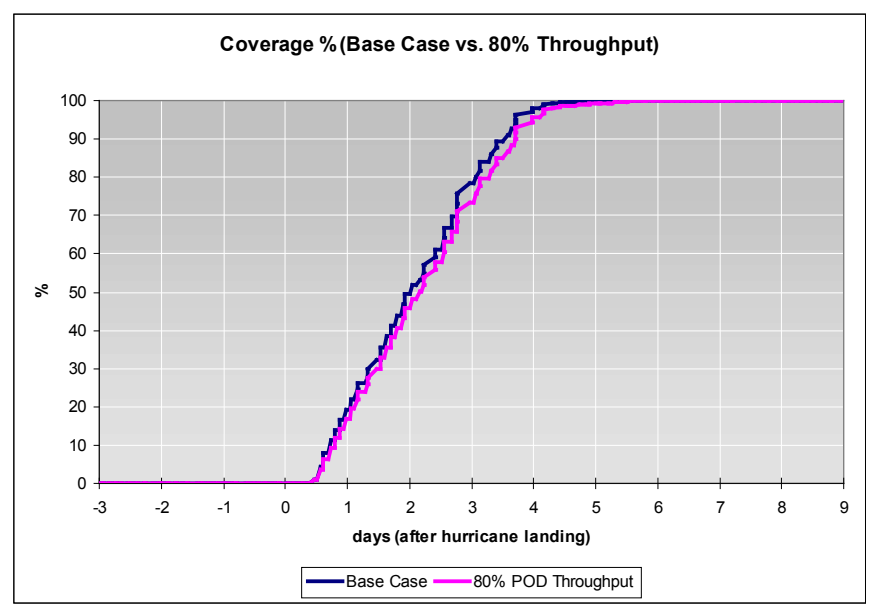

Figure 10: Coverage with Lower POD Throughput

\subsection{More Victims}

In this experiment, we simulate the impact of more victims ( $20 \%$ more than the base case) on the coverage. Note that in the base case, the total demand for water for a 3 day distribution operation is about 2.9 million liters while the total supply quantity for water is 4.04 million liters. Therefore, in this experiment the total demand would be 3.48 million liters while the supply quantity is the same as the base case. For this scenario, the $95 \%$ coverage was reached after 4.472 days, about 0.5 days later than in the base case. The coverage profile for this scenario is shown in Figure 11. This experiment shows that the number of victims has a significant impact on coverage.

\subsection{Optimal Dispatching of RSA Trucks to PODs}

A typical way to ship supply by trucks from RSA to PODs is a round robin method, i.e., dispatching trucks in a predetermined sequence In this experiment, we simulated the impact of optimal dispatching of RSA trucks on the coverage. 


\section{Lee, Ghosh and Ettl}

The optimal dispatching capability determines the best destination POD for each shipment from local staging area (e.g., RSA) considering: number of expected victims in each POD, supply (on-hand Inventory, In-transit inventory), transit time (distance, road conditions etc.), POD throughput rate for distributing emergency supplies. Figure 12 show the profile of the coverage for this scenario. The 95\% coverage was reached much faster, in 3.264 days, than in the case base under round robin, 3.805 days. This experiment indicates that the coverage can improve substantially when POD destination is selected optimally for each RSA outbound shipments.

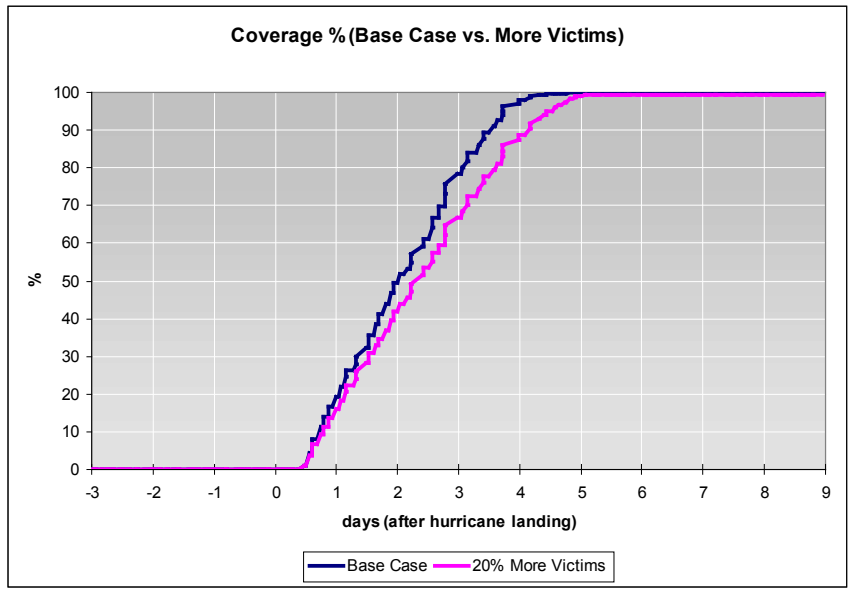

Figure 11: Coverage with 20\% More Victims

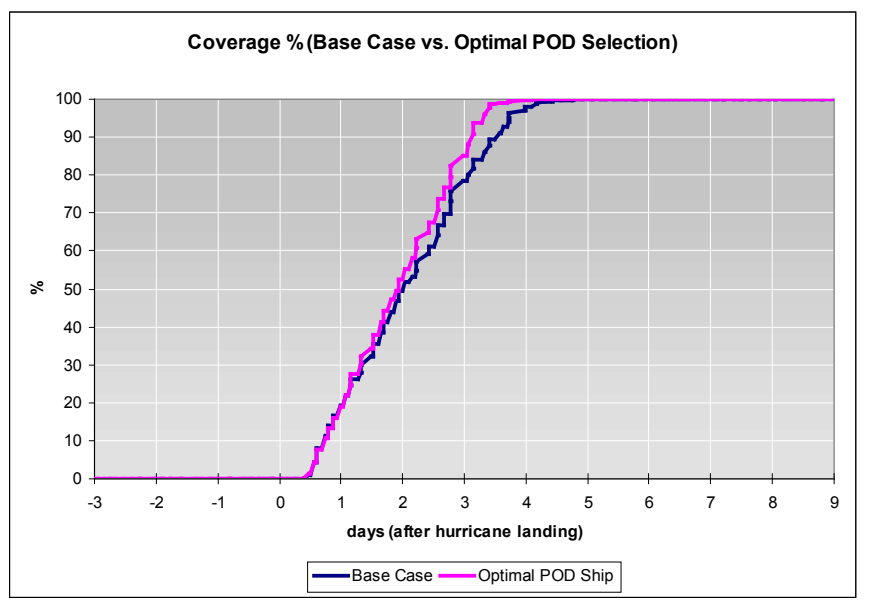

Figure 12: Coverage with Optimal Dispatching of RSA Ship

\subsection{Optimal Cross Shipping Between PODs}

During disaster response operations there will be an imbalance between supply and demand, i.e., certain PODs will experience shortage of supplies and certain other POD location will experience surplus, thus negatively impacting the coverage. One way to mitigate the imbalance is to deploy cross shipments (also called cross leveling of supplies) so that surplus in a POD is shipped to another POD that experiences a shortage. In this experiment, we simulated the impact of cross shipping on the coverage. We assume that there are 10 trucks available for cross shipping operations, the frequency of the cross shipping is every 2 hours, and the minimum batch size for cross shipping is 900 liters (one pallet). The simulation results indicate that with optimal cross shipping, the $95 \%$ coverage is reached after 3.43 days instead of 3.805 days in the base case. The coverage profile for this scenarios is shown in Figure 13. This result illustrates that cross shipping can substantially improve the coverage especially when supplies are constrained.

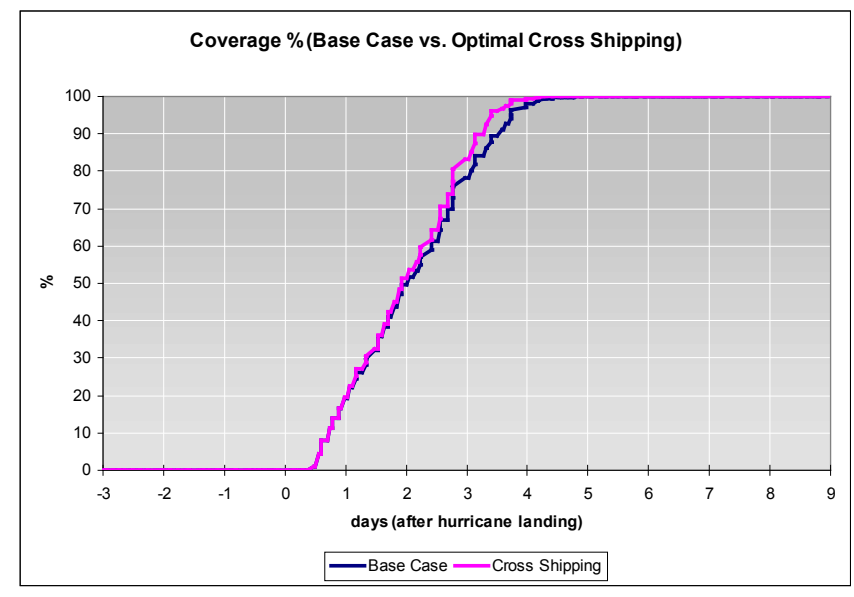

Figure 13. Coverage with Optimal Cross Shipping 
Lee, Ghosh and Ettl

\section{CONCLUDING REMARKS}

The effectiveness of disaster preparedness and response is difficult to estimate due to many uncertainties and dynamics involved in the supply chain, POD operations, progression of disasters and behavior of disaster victims. Simulation is a useful tool for analyzing, testing and developing effective emergency response plans. In this paper, we introduced a modeling framework, called i-DRuM, that uses simulation and optimization for effective analysis of disaster relief plans and operations. i-DRuM can provide insight into the way different variables and operational decisions impact response time and coverage during disaster response operations, and identify potential process improvements. From the simulation experiments and analyses, some improvement opportunities for disaster response planning were identified. Disaster relief supplies should be pre-positioned close to the potential disaster area in order to have fast response and improved coverage. Disaster response plans should have the flexibility to handle adverse situations like low POD throughput and large number of victims because the variability of POD throughput and victims' demand can be very high. There should also be a capability of handling shortage and surplus situations among PODs through more effective RSA dispatching and/or cross leveling among PODs. For future work, we plan to build a capability to input real time data such as traffic data, POD status, severity, location and speed disaster, number of victims and status of infrastructure such as electricity and communication network to the simulation model to be able to accurately update the simulation for operational decision support.

\section{REFERENCES}

AHRQ. 2004. Bioterrorism and Other Public Health Emergencies: Tools and Models for Planning and Preparedness: Community-Based Mass Prophylaxis, A Planning Guide for Public Health Preparedness, Agency for Healthcare Research and Quality. <http://www.ahrq.gov/research/cbmprophyl/cbmpro.htm\#down> [accessed March 25, 2008].

Aaby, K., J. Hermann, C. Jordan, M. Treadwell., and K. Wood. 2006. Montgomery County's Public Health Service Uses Operations Research to Plan Emergency Mass Dispensing and Vaccination Clinics, Interfaces, 36(6), 567-579.

Baker, E. J. 1991. Hurricane Evacuation Behavior. International Journal of Mass Emergencies and Disasters. 9(2), 287-310.

Bravata, D.M., Zaric, G.S., Holty, J-E.C., Brandeau, M.L., Wilhelm, E.R., McDonald, K.M., and D.K. Owens. 2006. Reducing Mortality from Anthrax Bioterrorism: Costs and Benefits of Alternative Strategies for Stockpiling and Dispensing Medical and Pharmaceutical Supplies," Biosecurity and Bioterrorism, Biodefense Strategy, Practice and Science, 4, 244262.

Caggiano, K., J. Muckstadt, and J. Rappold. 2006. Integrated Real-Time Capacity and Inventory Allocation for Reparable Service Parts in a Two-Echelon Supply System.

CDC. 2001. Smallpox Response Plan and Guidelines (Version 3.0). Centers for Disease Control and Prevention (CDC). $<$ http://www.bt.cdc.gov/agent/smallpox/response-plan/index.asp> [accessed March 25, 2008].

Craft, D. L., L. M. Wein, and A. H. Wilkins. 2005. Analyzing Bioterror Response Logistics: The Case of Anthrax. Management Science. 51(5), 679-694.

Ekici, A., P. Keshinocak, J. Swann. 2008. Pandemic Influenza Response, The Proceedings of the 2008 Winter Simulation Conference, S. J. Mason, R. Hill, L. Moench, and O. Rose, eds.

Graves, S., and S. Willems, 2003. Supply Chain Design: Safety Stock Placement and Supply Chain Configuration.

Green, L., and P. Kilesar, 2004. Improving Emergency Responsiveness with Management Science, Management Science, 50(8), 1001-1014.

Hupert, E. G., I. Mushlin, and M. A. Callahan. 2002. Modeling the Public Health Response to Bioterrorism: Using Discrete Event Simulation to Design Antibiotic Distribution Center, Medical Decision Making, 22(5), S17-S25.

Iqbal, Q., K. Mehler, and M. B. Yildirim. 2007. Comparison of disaster logistics planning and execution for 2005 hurricane season. A Report from Midwest Transportation Consortium. <http://www.ctre.iastate.edu/mtc/reports/disastermanagement.pdf $>$ [accessed March 6, 2009].

Kaplan, E. H., D. L. Craft, and L. M. Wein. 2002. Emergency Response to a Smallpox Attack: The Case of Mass Vaccination. Proceedings of the National Academy of Sciences, 99 10935-10940.

Kolesar, P., and W. E. Walker. 1974. An Algorithm for the Dynamic Relocation of Fire Companies. Operations Research. 22(2), 249-274.

Larson, R. C. 1974. A Hypercube Queuing Modeling for Facility Location and Redistricting in Urban Emergency services. Journal of Computers and Operations Research, 1(1), 67-95.

Larson, R. C. 2002. Public Sector Operations Research: A personal Journal. Operations Research, 50(1), 135-145.

Larson, R. C. 2004. O.R. Models for Homeland Security. OR/MS today, 31(5) 22-29.

Larson, R., M. Metzger, and M. Cahn. 2006. Responding to Emergencies: Lesson Learned and the Need for Analysis, Interfaces, 36(6), 567-579. 
Lee, E. K., S. Maheshwary, J. Mason, and W. Glissom. 2006. Large-Scale Dispensing for Emergency Response to Bioterrorism and Infectious-Disease Outbreak, Interfaces, 36(6): 591-607.

Lee, D. H., F. Yuan, S.-M. Chin, and H. Hwang. 2006b. Global Optimization of Emergency Evacuation Assignments, Interfaces, 36(6), 502-513.

Lee, Y.M., 2008. Analyzing Dispensing Plan for Emergency Medical Supplies in the Event of Bioterrorism, The Proceedings of the 2008 Winter Simulation Conference, S. J. Mason, R. Hill, L. Moench, and O. Rose, eds.

Miller, G., S. Randolph, and J. E. Patterson. 2006. Responding to Bioterrorist Smallpox in San Antonio, Interfaces, 36(6): 580-590.

Muckstadt, J. 2004. Analysis and Algorithms for Service Parts Supply Chains.

NHC (National Hurricane Center). $2009 . \quad$ Hurricane Preparedness. $<$ http://www.nhc.noaa.gov/HAW2/english/forecast/errors.shtml> [accessed March 23, 2009].

Rickter, A., and S. Khan. 2007. Preliminary Analysis of Alternate Modes of Dispensing for LA County, unpublished work, presented at INFORMS International Conference 2007.

Wein, L. M., D. L. Craft, and E. H. Kaplan. 2003. Emergency Response to an Antrax Attack. Proceedings of the National Academy of Sciences, 100 4346-4351.

Wein, L. M., and Y. Liu. 2005. Analyzing a Bioterror Attack on the Food Supply: The Case of Botulium in Milk. Proceedings of the National Academy of Sciences 102, 9984-9989.

Whitworth, M. H. 2006. Designing the Response to an Anthrax Attack, Interfaces, 36(6): 562-568.

Wright, P. D., M. J. Liberatore, and R. L. Nydick. 2006. A Survey of Operations Research Models and Applications in Homeland Security, Interfaces, 36(6): 514-529.

\section{AUTHOR BIOGRAPHIES}

YOUNG M. LEE is a Research Staff Member in the Business Analytics and Mathematical Sciences Department of IBM's T.J. Watson Research Center. Dr. Lee received B.S., M.S., and Ph.D. degrees in chemical engineering from Columbia University. He joined the IBM Research Division in 2002, and has been working in the areas of supply chain simulation and optimization. Prior to joining IBM, he had worked for BASF for 14 years, where he had founded and managed the Mathematical Modeling Group, and led development of numerous optimization and simulation models for various logistics and manufacturing processes. His research interest includes simulation and optimization of supply chain, manufacturing, services, workforce management, business processes and disaster response operations. His email is $<$ ymlee@us.ibm.com>.

SOUMYADIP GHOSH is a Research Staff Member in the Business Analytics and Mathematical Sciences Department of IBM's T.J. Watson Research Center. He obtained his doctorate in 2004 from the Operations Research and Industrial Engineering department in Cornell University, and has since been a member of IBM Research. His simulation research interests include theory and practice in particular on input dependence modeling and risk modeling, and simulation-based optimization techniques. His other interests are in the field of supply-chain analysis, and queueing theory based scheduling of large-scale production systems. He can be contacted at<ghoshs@us.ibm.com>.

MARKUS ETTL is a Research Staff Member in the Business Analytics and Mathematical Sciences Department of IBM's T.J. Watson Research Center. Markus joined IBM Research in 1995 after receiving his doctoral degree in Computer Science in 1995 from Friedrich-Alexander University in Erlangen, Germany. Since joining IBM, he focused on advanced research in supply chain management. His research interests include operations research, simulation, decision support for manufacturing logistics, and sense-and-respond business management for adaptive organizations. His email address is $<$ msettl@us.ibm.com>. 